\title{
Experiments with Forming Coated Sheets with Plasma-Chemical Pretreatment of the Surface
}

\author{
Emil Schwarzer, Milan Dvořák \\ BUT, Faculty of Mechanical Engineering, IMT, Brno, Czech Republic \\ Email: emil.schwarzer@seznam.cz,dvorak.m@fme.vutbr.cz
}

Received 25 April 2016; accepted 27 June 2016; published 30 June 2016

Copyright (C) 2016 by authors and Scientific Research Publishing Inc.

This work is licensed under the Creative Commons Attribution International License (CC BY).

http://creativecommons.org/licenses/by/4.0/

(c) $\underset{\mathrm{EY}}{\mathrm{E}}$ Open Access

\section{Abstract}

The article used new experimental equipment for effective testing of adhesion coatings on the sheets. Testing was performed in jig by bending roller with selected radius. In the context of experiments a multi-jet system was used. The aim of my previous publications and even this article is to achieve that by using of multi-jet plasma system, samples were achieved that will not be damaged coating after the bending. Specific coats on the sheets have been optimized composition of the plasma so that its result was the maximum adhesion of the coating to the steel base of samples. Results of experiments are presented in article. The article focuses on the tensile test and the result of the tensile test. All important values of tensile tests are published in this article. For example: elongation $A_{50}, A_{g}$, tensile strength $R_{m}$, and yield strength $R_{p 0.2}$. Results with values of tensile tests are also presented in this article. Selected coated steel samples were photographed in the clamped in jig on the tension device. Group selected samples were divided by the applied coating. First, the basecoat, the final coat and coat were treated with a multi-jet plasma system. From a previous publication graphs show the dependence of the strength on elongation of a sample. Further research will be focused on selected coated samples, where samples are etched onto the surface of a network and are bent in a special jig in range bending radius R11 to R35. After bending, the samples are examined at a special optical device and are evaluated deformation circles in straight and bent part of the samples.

\section{Keywords}

Nozzles, Bending, Multi-Jet Plasma System, Flow, Tensile Tests, Coating

\section{Introduction}

Base steel sheet and the coat are components that may or may not cooperate [1] [2]. When we talking about the

How to cite this paper: Schwarzer, E. and Dvořák, M. (2016) Experiments with Forming Coated Sheets with PlasmaChemical Pretreatment of the Surface. Journal of Surface Engineered Materials and Advanced Technology, 6, 118-124. 
technological forming operations, it can lead to disruption of the system of these pairs. This may cause disruption and peeling of the coating.

This can be a big problem between the base steel material and coat when forming of material. It can lead to defects such as deform the shape, fragility or improper choice of materials and coatings.

The basic parameter of these linkages is between basic material and coating, compliance forming parameters and in my case, optimization of forming operations and parameters forming processes. One way to do this is to apply a multi-jet plasma system and their use in combination material versus coating [3]-[7].

It means treatment of the surface by multi-jet plasma system.

\section{Experiments with Multi-Jet Plasma System I}

Brief description of how it works multi-jet plasma system I described in my previous publication. In cooperation with Masaryk University in Brno following experiments were conducted.

Selected samples were tested on the graduated bending jig, which allows testing surface-treated sheets [8]. This is possible through construction of the jig. Material of tested samples is steel with designation 1.0322 (DX56D), thickness $1 \mathrm{~mm}$. Mechanical properties $\mathrm{R}_{\mathrm{m}}=490 \mathrm{MPa}, \mathrm{A}=20 \mathrm{~mm}^{2}$. Samples from this experiment were divided into following groups, see Table 1 . The surface treatment of sheets samples with surface coated of plasma jets were modified by these inert and reactive gases: $\mathrm{Ar}, \mathrm{O}_{2}, \mathrm{~N}_{2}, \mathrm{CO}_{2}, \mathrm{Ar}+\mathrm{H}_{2} \mathrm{O}$.

Power was in range 550 - $600 \mathrm{~W}$, flow rate $40-50 \mathrm{l} / \mathrm{min}$, feed rate $3 \mathrm{~m} / \mathrm{min}$, number of passes-two times. So we can compare samples, because we had samples 1,2 and 3 as reference samples. Means not degreased samples. On these samples was not applied multi-jet plasma system method.

On the other test samples was applied modification of multi jet plasma system and above gases and their combination. In experiment was changed power in range 550 to $600 \mathrm{~W}$.

The flow rate had constant value $0.2 \mathrm{l} / \mathrm{min}$, feed rate was $3 \mathrm{~m} / \mathrm{min}$. During experiments were evaluated sheets for deep drawing according to Erichsen for sample 4, sample 14 and 17 (Figures 1-3).

On the sample 4 was used Argon gas. Damage of coating was under border IE $4 \mathrm{~mm}$.

Sample 14 with $\mathrm{Ar}+\mathrm{CO}_{2}$ has better result. Value IE $3.7 \mathrm{~mm}$ showed damage with smaller cracks on the coating. Experiments with medium $\mathrm{Ar}+\mathrm{H}_{2} \mathrm{O}$ which were applied on the sample 17 had the best result. Value coating damage according to Erichsen was stopped down to $7.5 \mathrm{~mm}$.

The resulting values for the other samples are given in Table 2. These are samples: Z1, Z2, Z3, TC1, TC2.

On the base metal sheet (BP) was applied plasma and then basecoat (KTL). The individual samples:

For a sample BP4 is interesting that the coating damage occurred to the border IE 10. For samples BP5 and BP6 these values have been halved. In these three samples was used as the basic gas Argon.

Demonstration bent selected sample with the damage of the coating after bending. In the selected sample No. 21 on Figure 4 where the bending was performed on a graduated bending jig. Damage was at the base coat and also topcoat [9]. Factors which damage coating there may be several. For example, poorly degreased base material, too small bending radius, not quite correctly applied the base coat or topcoat. Another parameter is of course gas composition for multi jet plasma system. In this case it was composition $\mathrm{Ar}+\mathrm{CO}_{2}$.

Table 1. BP—without coat, PL—plasma, Z—base, TC—top coat, w/a—without application.

\begin{tabular}{lccccccccc}
\hline SET & $26-30$ & $\mathbf{3 1 - 3 5}$ & $\mathbf{3 6 - 4 0}$ & $\mathbf{1 - 5}$ & $\mathbf{6 - 1 0}$ & $\mathbf{1 1 - 1 5}$ & $\mathbf{2 1 - 2 5}$ & $\mathbf{1 6 - 2 0}$ \\
\hline BP & BP & BP & $\mathrm{Z}$ & $\mathrm{Z}$ & $\mathrm{Z}$ & $\mathrm{TC}$ & $\mathrm{TC}$ \\
\hline
\end{tabular}




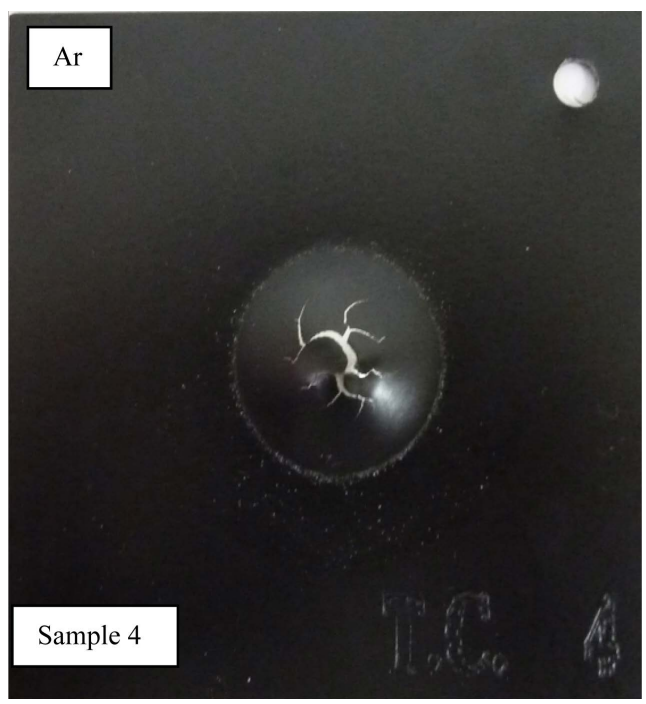

Figure 1. Sample 4: sheet steel $(90 \times 90 \times 1 \mathrm{~mm})$.

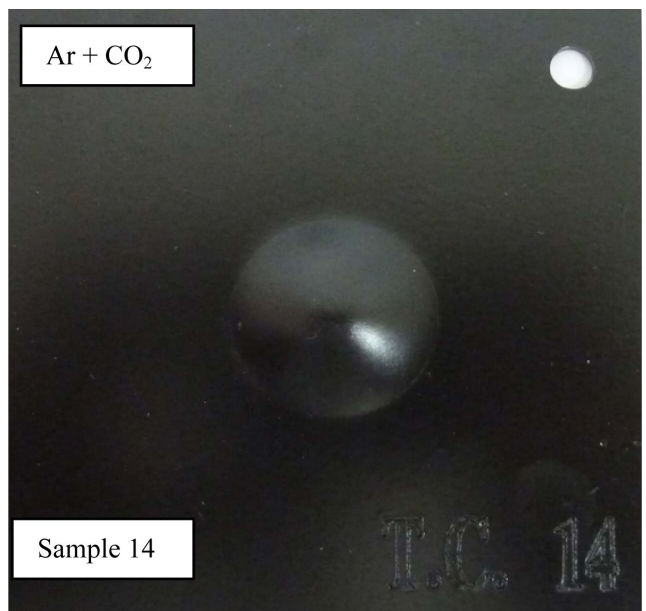

Figure 2. Sample 14 of sheet steel $(90 \times 90 \times 1 \mathrm{~mm})$.

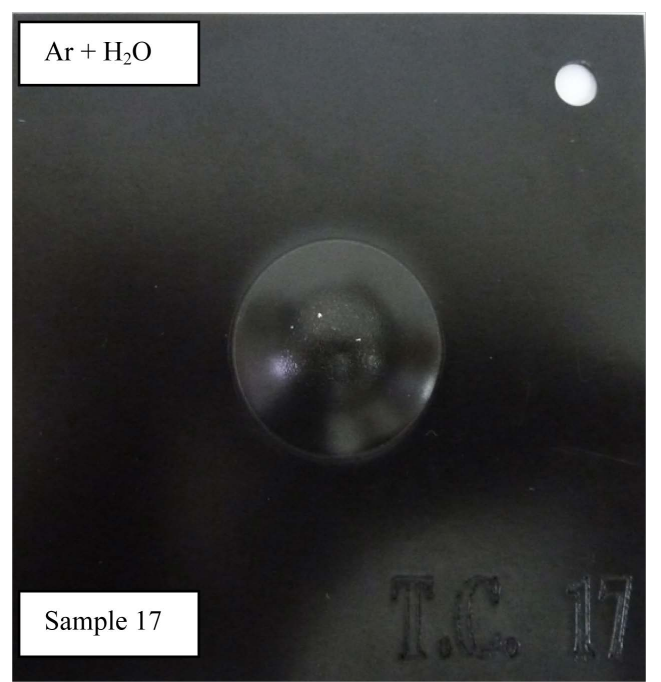

Figure 3 . Sample 17 of sheet steel $(90 \times 90 \times 1 \mathrm{~mm})$. 
Table 2. Measured values IE according to Erichsen Size of sample $90 \times 90 \times 1 \mathrm{~mm}$.

\begin{tabular}{cccccccccc}
\hline SAMPLES & BP4 & BP5 & BP6 & Z1 & Z2 & Z3 & TC1 & TC2 & TC3 \\
\hline MULTI-JET PLASMA SYSTEM & YES & YES & YES & NO & NO & NO & NO & NO & NO \\
DEEPENING IE [mm] & 9.75 & 4 & 6 & 6.85 & 4 & 7.1 & 2.89 & 3.27 & 11.6 \\
FUNCTIONAL & YES & YES & YES & YES & YES & YES & & YES \\
NON FUNCTIONAL & & & & & & & NO & NO \\
\hline
\end{tabular}

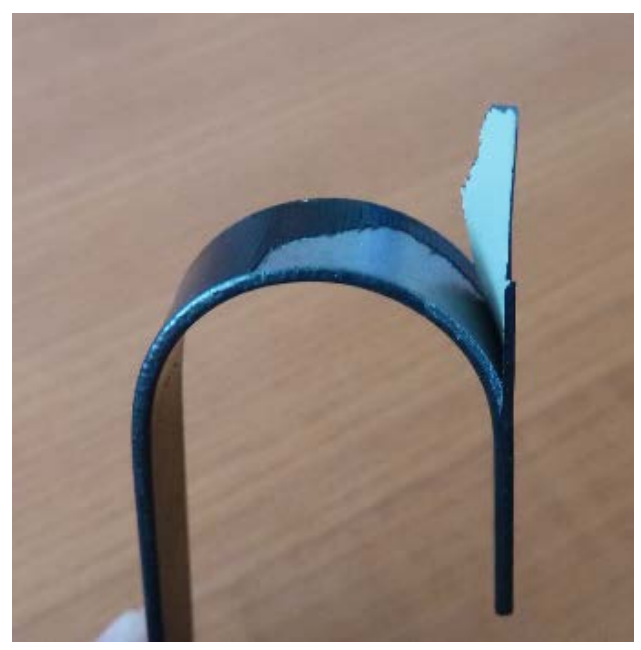

Figure 4. Sample number $21(\mathrm{TC}+\mathrm{PL})$. Chipped base + topcoat + plasma. Sample bent on a graduated bending jig with rollers.

\section{Experiments with Multi-Jet Plasma System II}

Selected samples with dimension $90 \times 10 \times 1 \mathrm{~mm}$ were tested for tensile test. Device for tested samples is 1200 UPC.

Before when we start with experiment, I categorized samples to the groups (Table 3) with a different composition of plasma. To the samples was welded plate to be clamped in a special jig on a tensile machine and were performed tensile tests and evaluated important parameters [10]-[14].

Sample BP11 with width [mm] and thickness b [mm] was clamped in special jig in tensile testing machine (Figure 5).

Test preparation included a thorough cleaning of the samples, the proper clamping on a tensile tester and correct setting of parameters. The test was performed so that the test samples were monitored throughout the test and when the sample was torn apart were from the tension diagram calculated parameters are given in Table 4.

\section{Conclusions}

To the individual parameters of the tensile tests and tensile testing machine, sample dimensions are a and b. Initial sheet thickness is $1 \mathrm{~mm}$.

E-Young module of elasticity is in the range 22.20 to $74.79 \mathrm{MPa}$.

For $\mathrm{R}_{\mathrm{p}}$ proof strength, English original is non-proportional extension. Value of proof strength is in the range 129.71 to $147.45 \mathrm{MPa}$.

$\mathrm{R}_{\mathrm{m}}$ is tensile strength. Initial material has adequate strength. Value tensile strength is in the range 253 to 265 $\mathrm{MPa}$. For plastic elongation $\mathrm{A}_{\mathrm{g}}$, English original is non-proportional elongation; value is in the range 9.98 to 21.85 for material 1.0322 (DX56D) [15] [16].

For elongation $A_{50}$, the best result was the elongation for the sample BP11 and TC6, and then followed the samples BP16, Z12, BP7, and TC9. Contraction Z is changing the cross-section with an extension in interval from 34.19 to 44.18 [\%]. Time to break the sample is t which is in the range 18.21 to 37.23 sec. Extensometer gauge length is $\mathrm{S}$. 
Table 3. Samples that have been treated with plasma and which were subjected to a tensile test.

\begin{tabular}{ccc}
\hline & Samples with plasma treatment & \\
BP11 & $\mathrm{A}_{\mathrm{r}}+\mathrm{N}_{2}$ & $\mathrm{BP}+\mathrm{PL}+\mathrm{Z}$ \\
BP16 & $\mathrm{A}_{\mathrm{r}}+\mathrm{H}_{2} \mathrm{O}$ & $\mathrm{BP}+\mathrm{PL}+\mathrm{Z}$ \\
BP7 & $\mathrm{A}_{\mathrm{r}}+\mathrm{O}_{2}$ & $\mathrm{BP}+\mathrm{PL}+\mathrm{Z}$ \\
TC6 & $\mathrm{A}_{\mathrm{r}}$ & $\mathrm{TC}+\mathrm{PL}$ \\
TC9 & $\mathrm{A}_{\mathrm{r}}+\mathrm{O}_{2}$ & $\mathrm{TC}+\mathrm{PL}$ \\
$\mathrm{Z} 12$ & $\mathrm{~A}_{\mathrm{r}}+\mathrm{N}_{2}$ & $\mathrm{Z}+\mathrm{PL}+\mathrm{TC}$ \\
\hline
\end{tabular}

Table 4. Measured values for selected samples after tensile test.

\begin{tabular}{cccccccccccccc}
\hline Samples & $\begin{array}{c}\mathbf{a} \\
{[\mathrm{mm}]}\end{array}$ & $\begin{array}{c}\mathbf{b} \\
{[\mathrm{mm}]}\end{array}$ & $\begin{array}{c}\mathbf{E} \\
{[\mathrm{MPa}]}\end{array}$ & $\begin{array}{c}\mathbf{R}_{\mathbf{p}} \\
{[\mathrm{MPa}]}\end{array}$ & $\begin{array}{c}\mathbf{R}_{\mathbf{m}} \\
{[\mathrm{MPa}]}\end{array}$ & $\begin{array}{c}\mathbf{A}_{\mathbf{g}} \\
{[\%]}\end{array}$ & $\begin{array}{c}\mathbf{A}_{\mathbf{5 0}} \\
{[\%]}\end{array}$ & $\begin{array}{c}\mathbf{Z} \\
{[\%]}\end{array}$ & $\begin{array}{c}\mathbf{t} \\
{[\mathrm{s}]}\end{array}$ & $\begin{array}{c}\mathbf{s} \\
{[\mathrm{mm}]}\end{array}$ & $\begin{array}{c}\mathbf{F} \\
{[\mathrm{kN}]}\end{array}$ & $\begin{array}{c}\mathbf{d L} \\
{[\mathrm{mm}]}\end{array}$ & $\begin{array}{c}\mathbf{R}_{\mathbf{m}} \\
{[\mathrm{MPa}]}\end{array}$ \\
\hline BP11 & 13.1 & 1.0 & 68.52 & 129.71 & 259.0 & 21.85 & 42.18 & 43.01 & 31.44 & 17.11 & 3.3 & 14.66 & 249.71 \\
BP16 & 12.7 & 1.0 & 74.79 & 135.87 & 258.0 & 11.93 & 37.70 & 34.19 & 35.91 & 17.21 & 1.5 & 10.35 & 117.45 \\
BP7 & 13.20 & 1.0 & 22.20 & 143.91 & 253.0 & 9.98 & 29.44 & 39.20 & 37.23 & 19.12 & 2.7 & 10.15 & 207.82 \\
TC6 & 13.80 & 1.0 & 38.38 & 136.70 & 256.0 & 15.44 & 42.04 & 44.18 & 20.05 & 11.96 & 3.5 & 9.26 & 249.65 \\
TC9 & 12.3 & 1.0 & 68.90 & 138.32 & 263.0 & 18.22 & 27.37 & 42.48 & 18.21 & 9.74 & 3.2 & 7.28 & 257.74 \\
Z12 & 13.20 & 1.0 & 64.50 & 147.45 & 265.0 & 14.73 & 32.23 & 43.01 & 18.90 & 7.72 & 3.4 & 5.76 & 259.00 \\
\hline
\end{tabular}

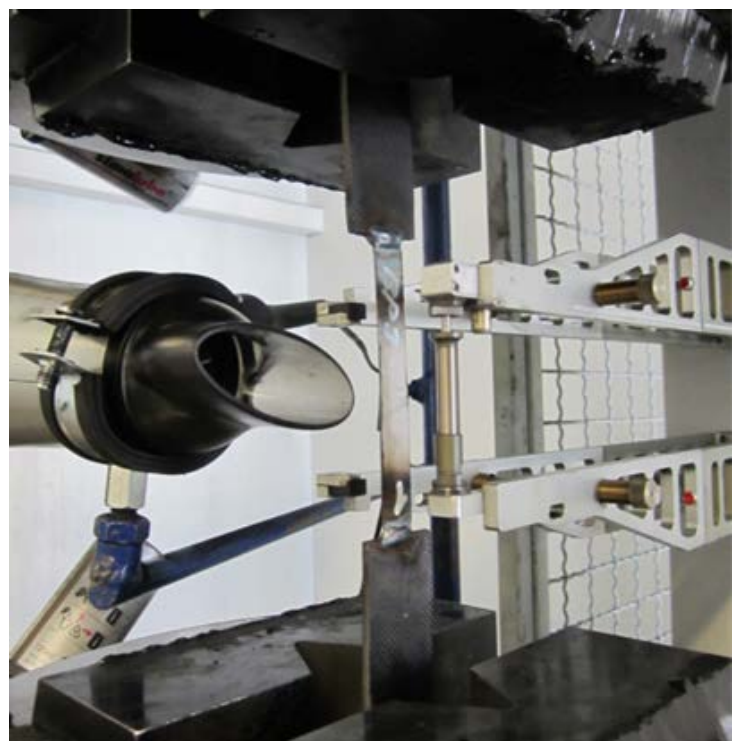

Figure 5. Example of sample which was subjected by tensile test.

The highest load $\mathrm{F}$ is at which samples are loaded. Elongation at maximum force is dL. The parameters from tensile test are evaluated on the device UPC-1200.

Article discusses possible solutions formability sheet and bending sheet metal with organic coatings with one or more layers in interacting with a metal base.

Experiments are focusing in this article on the Erichsen tests and testing on tensile testing machine.

Another benefit of these samples on a bend on the graduated bending jig is functional samples without damage of the applied coating in the bend area.

For this purpose optimization of the composition of the input components of plasma was made. This generally leads to higher excavating identified by Erichsen test according to ISO 20482 [17]. 
During technology operations, forming occurs for these units for disruptions of common bonds.

Disruption between the base steel material and the coating makes defects occur in plate forming (inadequate structure of the surface, brittleness, metal release, shape deformation, waviness of the plate surface) or a combination of poor choice of base material and coating.

Important and actual requirements for coating technologies are to maintain the integrity of the surface layer and bonds between the surface and the base material after the drawing or bending [18] [19].

Functional molding with surface treatment is achieved by optimizing of the selected technological parameters of the process and those parameters will be part of the doctoral dissertation [20] [21].

This article presents another basic criterion tensile test to detect adhesion of organic coatings in one or more layers in the interaction with the metal base.

Experiments in tensile machine have shown that in combination applied coatings with the base material and combination of various gases are different and they have a different result in the tensile tests.

Anyway, for that experiment we could say that using a multi-jet plasma system, the selected samples are durable in terms of adhesion, especially for the sample BP11. This sample from material 1.0322 (DX56D) which has been properly degreased was judged the best in combination of gases $A_{r}+N_{2}$. On the base steel sheet was applied through nozzles multi-jet plasma system in combination $A_{r}+N_{2}$. This combination is in the article marked with the abbreviation $\mathrm{BP}+\mathrm{PL}+\mathrm{Z}$ that means: $\mathrm{BP}$ - base material (raw material), PL—multi-jet plasma system $\left(A_{r}+N_{2}\right)$, Z-basecoat.

\section{Acknowledgements}

The article was published by the support of the Faculty of Mechanical Engineering: BUT FME-S-12-5 from 2012 and VAV 13313. Acknowledgements for Brno University of Technology who financed this technical article. Thank also Masaryk University which enabled us to make experiments with multi-jet plasma system.

\section{References}

[1] Dvořák, M., et al. (2001) Technology II. Academic Publishing CERM, Ltd., Brno, 236-238.

[2] Blanks, T. (1985) Metals Handbook: Mechanical Testing. American Society for Metals, 837-842.

[3] ČSN EN 13144 (2003) Metallic and Other Inorganic Coatings: Method for Quantitative Measurement of Adhesion for Tensile Test. Czech Standards Institute, 12-13.

[4] Patent EP 1077021, US 6525481 (2005) Method of Making a Physically and Chemically Active Environment by Means of a Plasma Jet and the Related Plasma Jet. Masaryk University, Brno, 6.

[5] Hušek, M. and Dvořák, M. (2010) Test of Adherence Multifunctional Coating on the Sheet Using a Graduated Bending Jig. Engineering Technology, 15, 15-20.

[6] Dvořák, M. and Schwarzer, E. (2012) New Methods Testing of Adhesion of the Coating to Sheet Metal by Bending. Journal of Surface Engineered Materials and Advanced Technology, 2, 61-64. http://dx.doi.org/10.4236/jsemat.2012.22011

[7] Dvořák, M. and Schwarzer, E. (2013) Study of Formability of Coated Sheets from the Plasma Chemical Pretreatment of Surfaces. International Journal of Engineering and Innovative Technology, 3, 356-360.

[8] ČSN EN ISO 1519 (2002) Paints Substance-Bend Test (Cylindrical Mandrel). Czech Standards Institute.

[9] Test of Resistance of Coatings (2004) Measuring Equipment, Thickness, Hardness, Gloss Meters, Thermometers. Proinex Instruments, Ltd. Ostrava.

[10] Čada, R. (1998) Surface Formability of Metallic Materials. Technical University of Ostrava, Ostrava-Poruba, 90-92.

[11] Forejt, M. and Píška, M. (2006) Theory of Machining, Molding and Tool. CERM, Academic Publishing, Ltd., Brno, $225-226$.

[12] Kraus, V. (2000) Surface Modification. University of West Bohemia, Plzeň, 218-220.

[13] Kreibich, V. (1996) Theory and Technology of Surface Treatment. Publishing House of CVUT, Prague, 89-92.

[14] ČSN EN ISO 7438 (2005) Metallic Materials Bend Test. Czech Standards Institute, 11-12.

[15] Prysiazhnyi, V., Svoboda, T., Dvořák, M. and Klíma, J. (2012) Aluminum Surface Treatment by the RF Plasma Pencil. Surface and Coatings Technology, 206, 4140-4145. http://dx.doi.org/10.1016/j.surfcoat.2012.04.010

[16] ČSN EN 10002-1 (2002) Metallic Materials-Tensile Testing-Part 1: Method of Test at Ambient Temperature. Czech Standards Institute, 6-7. 
[17] ČSN EN ISO 20482 (2004) Metallic Materials—Sheet and Belts—Bulge Tests According to Erichsen, Czech Standards Institute, Prague.

[18] Krejčík, V. (1988) Surface Treatment of Metals II. Publishing House of Technical Literature, Prague.

[19] ČSN ISO 24213 (2009) Metallic Materials_-Sheets and Belt: Evaluation Method of Suspension for Flexural Bending. Czech Standards Institute, 14-15.

[20] Hermann, F. and Schiller, M. (2007) Testing of Paints and Protective Coatings. SYNPOas, Pardubice.

[21] Samek, R. (1988) Analysis of the Limit State of Plasticity and Technological Formability. University of Defence in Brno, Brno, 230 p.

\section{Submit or recommend next manuscript to SCIRP and we will provide best service for you:}

Accepting pre-submission inquiries through Email, Facebook, Linkedin, Twitter, etc A wide selection of journals (inclusive of 9 subjects, more than 200 journals)

Providing a 24-hour high-quality service

User-friendly online submission system

Fair and swift peer-review system

Efficient typesetting and proofreading procedure

Display of the result of downloads and visits, as well as the number of cited articles

Maximum dissemination of your research work

Submit your manuscript at: http://papersubmission.scirp.org/ 